\title{
Chapter 5 \\ Co-production in Action: The Case \\ of an Italian Residential Care Home
}

\author{
Gaia Bassani, Cristiana Cattaneo and Giovanna Galizzi
}

\subsection{Introduction}

Co-production is an increasing debate within public management. "It goes to the heart both of effective public service delivery and of the role of public services in achieving other societal ends - such as social inclusion or citizen engagement" (Osborne et al. 2012). The recent financial crisis puts emphasises on governments' needs to find new methods for managing public services (Kickert 2012). After the focus on New Public Management (NPM) and other waves of reforms and fashion approaches, co-production is one of the most powerful ways to reach a good performance of services (for citizens) at a lower cost. In fact, in this way the organisation or the public authorities could focus on detailed needs of citizens according to their priorities. At the same time citizens could be their-selves a resource for the design and the delivery of the service.

Literature confers different meanings to the co-production process, even if this process is perceived as something external to the delivery of a public service. Traditionally, the social and, above all, the health care settings consider clients as passive receivers of the care (Abma and Baur 2014). Furthermore, it appears that an over-professionalization of care is at work in these contexts. Recently, in the study of the health and social care domain, some authors, first of all Osborne and Strokosch (2013), suggest to focus on a relational approach. This approach consists in stimulating the empowerment of service users creating a positive social environment. As Alford (2009) argues, the intrinsic interaction in this case is viewed as an ongoing process where the relation is not "one-off", as in the transactional perspective. The majority of public sectors dealings are ongoing because there is a deep involvement of mutual personal knowledge, engagement and interactions among the actors. Similar to Alford (2009), Abma and Baur (2014) say

G. Bassani $(\bowtie) \cdot$ C. Cattaneo · G. Galizzi

University of Bergamo, Bergamo, Italy

e-mail: gaia.bassani@unibg.it

(C) The Author(s) 2016 
that care-ethics starts from a relational view on human beings. Thus, the relational approach entails the need for connectedness and dialogue, both among users and between users and service staff.

Based on this approach, Osborne and Strokosch's (2013) propose a reconceptualisation of the nature of health and social services with the contribution of all the actors. Actors (e.g., physicians, nurses, managers, families, residents) could be engaged in the delivery or in the creation of the service, respectively. Actors could co-produce at the operational or the strategic level. Previously, this perspective was already adopted by some authors (Bovaird 2007; Carman et al. 2013; Scott and Baehler 2011), although they labelled these levels differently. For example, Bovaird (2007) argued that co-production activities could be viewed as logistic and governance drivers; or Carman et al. (2013) introduced the direct care perspective and organisational design-governance together with policy making as a more strategic perspective. Although the object of analysis is different, both these levels entailed the interaction and the active participation of actors.

Moreover, in the panorama of contributions referring to factors of co-production (Abma and Baur 2014; Alford 2014; Bovaird 2007; Bovaird and Loeffler 2012; Carman et al. 2013; Dunston et al. 2009; Gilardi et al. 2014; Sorrentino et al. 2015; Verschuere et al. 2012), some authors have proposed a range of motivations, facilitators, key variables and barriers to co-produce. There are just a few attempts to systematise these factors by associating each of them with the level of analysis (Gilardi et al. 2014; Verschuere et al. 2012).

Although the proposed studies take the relational approach and/or the peculiarities of the third sector into consideration, authors still have not clearly shown how this understanding of the co-production process works in practice. Thus, taking this broad perspective, the present contribution is the exploration of contingencies arising from the distinctions occurring when co-production is seen through various lenses. Specifically, adopting Osborne and Strokosch's (2013) point of view, the paper aims, firstly, at tracing out factors related to both the operational and strategic levels of analysis and, secondly, at identifying intertwined factors that enhance co-production at both levels.

The resulting framework of analysis has implications both for academics and for practitioners. Theoretically, it acts firstly as stimulus for enhancing innovative modalities of services and secondly as a map for integrating different literature and results. Empirically, the framework could drive managers and consultants to plan and execute co-production relationships, and policy makers to take the activities working at operational level into consideration.

Both scholars and practitioners could also benefit from a field exploration of factors in a 67-bed Italian residential care home involved in an important process of change. The methods applied to recognize the factors in the case study mostly follow the relational approach: one formal meeting, frequent informal meetings, the analysis of documents and familiarity of the context by one of the researchers. The period of data collection and analysis covers 2 years and a half. 
The remainder of this chapter is organised as follows. Section 5.2 describes the levels and factors discussed in the co-production literature on health and social care domain. Section 5.3 provides a description of the case of the residential care home. Section 5.4 discusses findings and Sect. 5.5 presents the conclusion.

\subsection{Co-production in the Social and Health Domain}

The concept of 'co-production' is taking place more and more in public services, including new approaches to adult social and long-term care. As described in the Chap. 1 of the book, we refer to health and social care interpretations of co-production. In this domain, the concept of co-production is confused with that of patient engagement. In fact, as Barello et al. (2014) point out, it is difficult to define patient engagement because authors often use synonyms when describing their empirical analysis. One of the reasons for the poorly controlled proliferation of different concepts is that in services the distinction between production and consumption cannot always be separated. In fact, according to Fledderus et al. (2015) services cannot be produced in a standard way, the service results from the ongoing interaction between the user and the provider.

As the interaction is a social process, the distinction between consumption and production as far as time and place are concerned is beyond human control. Osborne and Strokosch (2013) refer to residential care homes as one of the most appropriate fields of study in which "direct face-to-face contact between the service user and the service provider" can be observed. In these settings, co-production activities appear guided by a relational framework (Abma and Baur 2014). Participation contributes towards creating a positive social environment in which care is perceived as a human need and an activity essential to well-being. Consumers, professionals are all involved together within the service development process (Dunston et al. 2009). Providers in this sense are not the only insiders of the process, as in the traditional health care approach. The professional knowledge required from the doctors, nurses and managers is continuously combined with the knowledge of the inherent in the patient him/herself. The context, thus, appears characterized by intense relationships and mutual support between actors of the health care process.

In this perspective, the distinction between the different phases of engagement introduced by various authors also appears confused. As Osborne and Strokosch (2013) suggest with their theoretical framework regarding enhanced co-production, there are, basically, two different levels of co-production. The operational level refers to the inseparability of consumption and production activities as pointed out before. The strategic level is more concerned with the intention to affect the strategic design of the service. In this way, the public service system could address users' needs more effectively in the future.

Thus, the enhanced co-production is based on a relational approach and entails both operational and strategic understanding. This perspective highlights the ideas 
offered by Bovaird (2007), Carman et al. (2013) and Scott and Baehler (2011). Bovaird (2007) adopts organisational motivations distinguishing logistical (or feasibility) drivers from governance drivers. Respectively, the first drivers arise when some services cannot effectively be delivered and the second drivers respond to declines in governance capacity at local or national settings. Carman et al. (2013) examine the patient engagement (patient engagement includes patients, families, their representatives, and health professionals) as a continuum from consultation to shared decision-making. Due to the involvement of the actors, the information flows among the service users, service providers and the system increase along the entire continuum. This continuum is guaranteed by the engagement, firstly, at the individual level, secondly, at the organisational design and governance level and, thirdly, at the policy-making level. At the individual level, namely in direct care, engagement implies an integration of patients' values, experiences and expectations with diagnosis and daily treatments. At the organisational design and governance level, patients' values, backgrounds and perspectives are combined with the design and governance of health and social care organisations. Finally, at the policy-making level, patients participate in the development and evaluation of health care policies and planning. Scott and Baehler (2011) mention the distinction between the responsive and operational levels of public policy. Osborne and Strokosch (2013) in their theorisation label the two levels introduced by Scott and Baehler (2011) as operational and strategic domains respectively.

Analysing studies that pay attention to factors of co-production (Abma and Baur 2014; Alford 2014; Bovaird 2007; Bovaird and Loeffler 2012; Carman et al. 2013; Dunston et al. 2009; Gilardi et al. 2014; Sorrentino et al. 2015; Verschuere et al 2012), some considerations may be outlined.

- First, studies use different names to identify factors that display co-production in action. These factors refer to actions, processes, structures (Carman et al. 2013) and intangible aspects. Moreover, they are usually categorized as motivations, facilitators, key variables and barriers.

- Secondly, the factors described by the various authors have an intrinsic balance between tangible and intangible elements. For example, in some cases, authors describe specific actions on the field, while in other cases they mention just trust, or values and skills.

- Thirdly, the health and social care domain, under the co-production umbrella, mostly involves in-depth operational level studies or theoretical contributions about governance processes and actions.

- Fourthly, some factors could work for co-production both at the operational and strategic level (i.e., intertwined factors). Moreover, these factors are responsible for enhancing a bilateral construction of co-production processes and activities at the operational and at the strategic level. Considering the relational approach, the interactions between users and providers create the ground for innovative services and decision-making processes. Thus, factors working at both levels increase co-production activities. 
Some authors, such as Gilardi et al. (2014) and Verschuere et al. (2012) provide a sort of systematisation of these factors through both levels. In fact, Gilardi et al. (2014) mention how the collaborative treatment works and show how chronic patients participate with physicians in decisions about their disease. Moreover, the study introduces the organisational level, considering how chronic patients' desires could affect the re-organisation of the entire health care service. Other authors consider the identification of core elements that reveal co-production in action. Verschuere et al. (2012), for example, focus on discovering elements (i.e., key variables) that make co-production effective. They refer to conditions under which co-production takes place (Ostrom 1990) and they deepen the analysis by referring to intra-organisational conditions, such as work processes and types of involved organisations. With work processes, the authors refer to a radical innovation of the entire organisational processes. All the processes have to be strategy-oriented and the clients are the object of attention of each process and activity. The second condition they mentioned, refers to the debate concerning how types of organisations (i.e., third sector, public and for-profit organisations) facilitate co-produced activities. Due to the lack of comparative studies, the debate is still unsolved.

In the light of the above considerations, we show in Table 5.1 firstly, the factors that work at the operational ${ }^{1}$ and at the strategic levels of analysis and, secondly, they identify intertwined factors that enhance co-production at both levels. We are aware that some factors could contain both operational and strategic aspects.

\subsection{The Case of a Residential Care Home}

Hereinafter the research process (Sect. 5.3.1), the research context (Sect. 5.3.2) and then the empirical results concerning the factors of co-production revealed by the case (Sect. 5.3.3) are described.

\subsubsection{Research Process}

The results of the majority of studies about co-production originate from either an in-depth theoretical analysis (Alford 2014; Barello et al. 2014; Bovaird and Loeffler 2012; Dunston et al. 2009; Fledderus et al. 2015; Osborne et al. 2012; Osborne and Strokosch 2013) or a fieldwork description (Bovaird 2007; Gilardi et al. 2014; Needham 2008; Sorrentino et al. 2015).

\footnotetext{
${ }^{1}$ As this study follows the distinction introduced by Osborne and Strokosch (2013), we aggregate both individual and collective factors at operational level. Consequently, we partially follow the categories introduced by previous studies (Gilardi et al. 2014; Sorrentino et al. 2015; Bracci and Chow 2016, Chap. 4 of this book).
} 


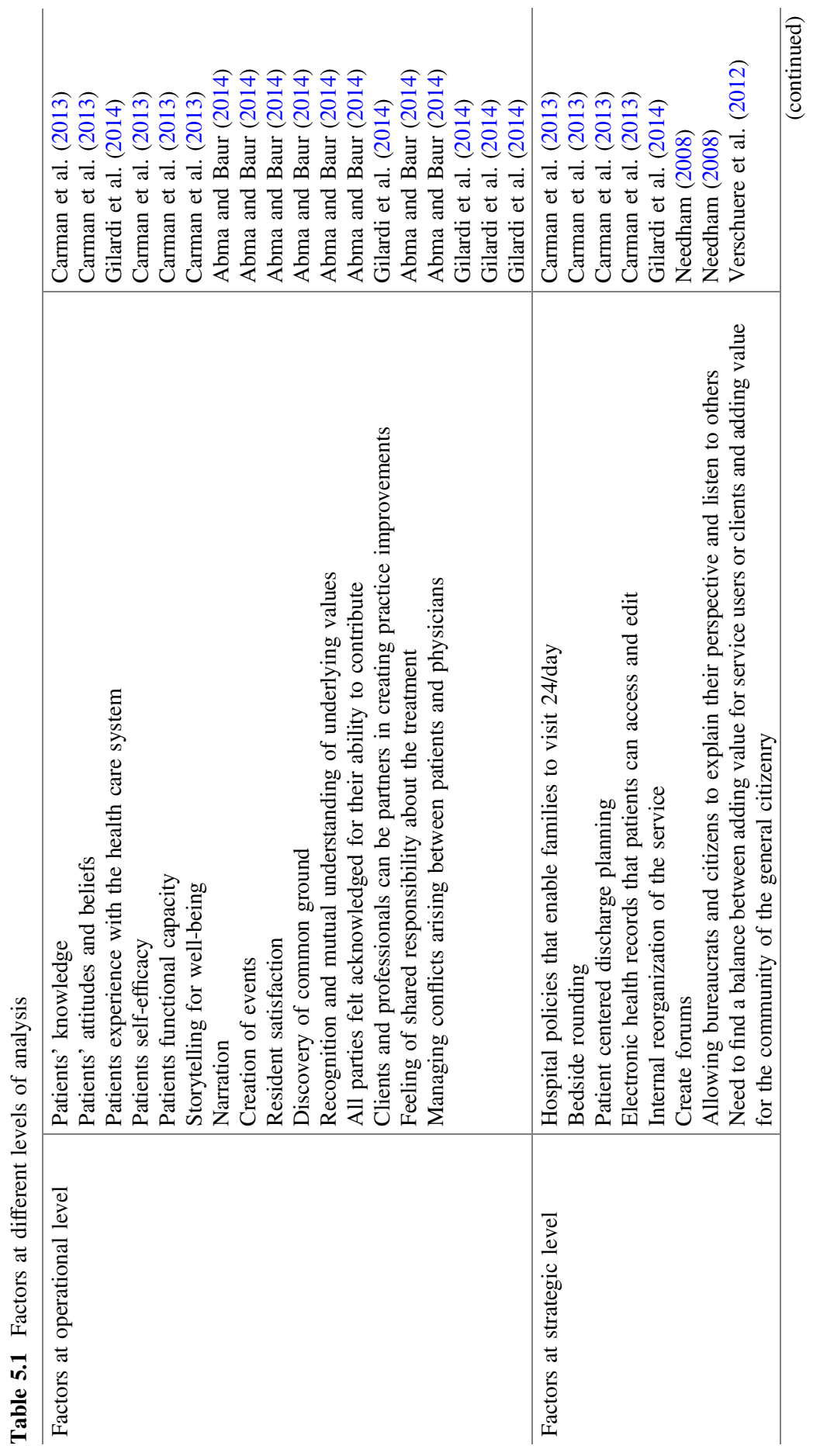




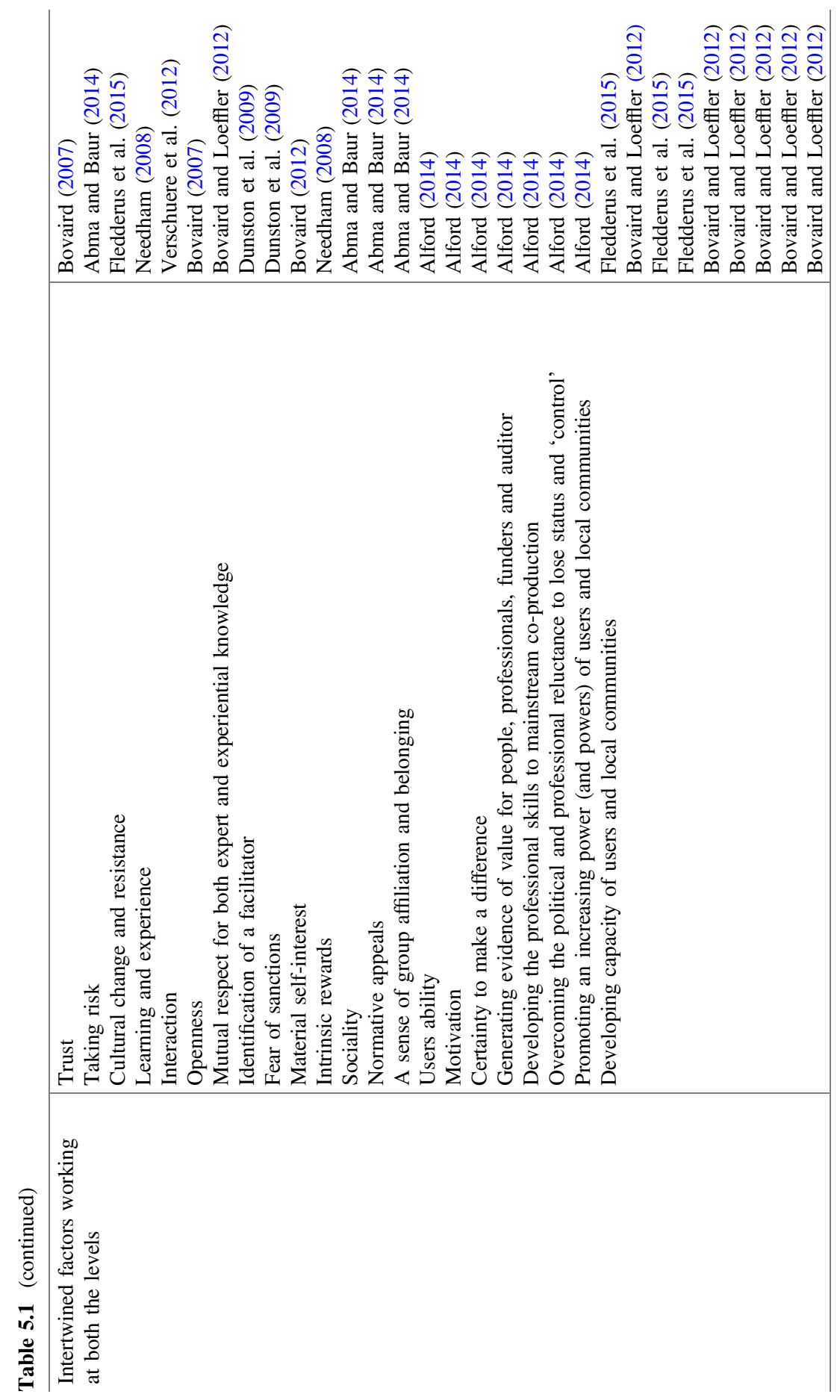


In view of the purpose of this paper, we chose to conduct the case study analysis through a qualitative inquiry method. The research was conducted in a small residential care home for the elderly (67 beds) in northern Italy. The majority of residents have physical disabilities but they do not have mental illness. As Osborne and Strokosch (2013) suggest, a residential care home is an appropriate example for exploring co-production activities through a relational approach. Furthermore, Burns et al. (2012) point out that the experiences of the elderly in care homes remain an under-researched area.

Concerning the methods of inquiry, the researchers based their analysis on documents, informal meetings, observations and interviews. Data were collected from December 2012 to May 2015. This process was facilitated by the fact that one researcher has a relative among the residents. In fact, she/he was able to collect data during informal conversations (i.e., meetings with his/her relative, the relatives of other residents, the service staff and local government citizens informed of the residential care home facts) and through observations.

Simultaneously, all the researchers collected documents about the setting and, in particular, about the organisational change under way, the strategic projects for the future of the residential structure and the new managers, and on the relationships between the residential care home and the local government. This process was driven by some information collected during a formal meeting with the President of the residential care home.

Since the collected storylines follow different points of view (i.e., users' view, providers' view and citizens' view), triangulation activities were extremely important throughout the entire process of inquiry. Triangulation has been generally considered a process of using multiple perceptions to clarify meaning, verifying the repeatability of an observation or interpretation (Denzin 1970). In fact, through triangulation of notes taken during informal meetings and of documents, we clarified the various meaning given to terms and concepts by identifying the different ways the process of change and activities are seen. Thus, the co-production characteristics of the health and social care service emerge from the case.

\subsubsection{Research Context}

The residential care home investigated is located in a municipality in northern Italy. The residential care home was founded thirty years ago and although it has been a private foundation since 2003, it pursues public goals and receives public funds from the local and regional government. The transformation into a private foundation is the result of a national and regional welfare reform in the third sector launched in 2003. Governance relationships with the local government are well established. The mayor of the municipality in which the residential care home is located nominates both the president and the board of directors. This fact guarantees that the residential care home is at the service of the local government citizens who pay lower fees than neighbouring local government citizens do. Furthermore, the 
mayor could, for example, pass an ordinance to admit a citizen to the residential care home at the local government's own expense. The residential care home cannot refuse this ordinance.

For three years, this context has undergone profound changes regarding the management of all the processes. In July 2012, the mayor nominated both the president and the board of directors. This fact stimulated an important organisational change of the residential care home. As a consequence of this change, the chief medical officer and the supervisor changed as well. For 25 years, all the services were provided by a cooperative that has its own nurses, social assistants, health workers and other service staff. The contract with this cooperative ended in January 2013. Subsequently, the new president and the new chief medical officer worked with this cooperative only for 6 months.

During that period, given the change in the legislation and the non-compliance of the structure in terms of quality-safety standards, the president and the chief medical officer intensified their relations with the service staff in order to have a better understanding of the existing organization. If, on the one hand, the change led to improvements in the conditions of the residents, on the other hand, at that time, the initiatives appeared "not to be in favour of the residents", but rather in favour of a general rationalization of operating costs.

After a few months, due to the rationing of leisure activities, the reduction of time that residents stayed out of bed and the change of the care treatments, the residents became unhappy. During that time, guests and families were obviously upset and the president and members of the board of directors understood that the changes had led to a deterioration in the quality of care. Thus, in January 2013, the chief medical officer resigned and the contract with the cooperative expired. Since February 2013, a new cooperative has taken over, while in May a new chief medical officer was appointed. He is a geriatrician and is currently working in the organisation.

The centrality of residents' needs has been the general philosophy of the cooperative since its origins. After the first years of activity, the cooperative focused on health and social care services gaining experience in the management of residential care homes. In 2013, the cooperative had 360 workers with a turnover of approx. 10 million euro. The staff provides a complete service for the residents (i.e., health and social services, catering, laundry services, etc.).

Although the cooperative intended to improve the service to the residents, in April 2013, the families complained about a deep sense of confusion. In fact, low levels of assistance and the new activities did not find the residents' nor the relatives' approval. Family members complained profusely for about a month and a general state of dissatisfaction was evident (both inside and outside the residential care home). Some relatives complained directly to the president especially in cases where health care was considered as insufficient. The president, therefore, decided to convene a meeting to explain the changes that were occurring and to introduce the cooperative. This episode put the patients at the centre of the delivery of care.

From February 2013 to date, the main organisational changes affecting the establishment of a process of co-production have been: 
- The re-organization of processes and activities that directly or indirectly involves the patients;

- The introduction of a physiatrist to support two physiotherapists already present in the home;

- The employment of an additional doctor to increase health care coverage. During the leisure activities this doctor wears a white coat to give a greater sense of security to the patients;

- The opportunity to discuss the care process with the chief medical officer who receives family members half an hour a day, 3 days a week;

- The introduction of a nursing manager, who coordinates the professional staff of the structure, is the referent in case of health issues with physicians and who provides information on the patients' health to the staff at the change of shift. Furthermore, the nursing manager is the person to whom all internal departments refer and also acts as the interface with family members for every need and request;

- The inclusion of a psychologist for the patients as well as for family members;

- The opportunity for a primary care physician in the town to visit the home whenever she/he wants. The doctor is very well known and well-liked by the people;

- The increase in the hours of leisure activities (from $20 \mathrm{~h}$ to $30 \mathrm{~h} / \mathrm{week}$ );

- The establishment of an intranet system to share patients' documents.

From a cost point of view, these improvements in the management of the services led to an increase in fees in January 2014 and September 2014. In addition, since June 2014, the residential agreement was modified to include a fee for new entrants to cover the laundry service. After that, the president formally reassured the family members that there would be no further increases in the residential fees.

\subsubsection{Empirical Results Regarding Co-production}

The origin of the co-production process was the meeting held in April 2013 by the president of the residential care home. In particular, the meeting was an opportunity for both residents and relatives to highlight their dissatisfaction about actions introduced and that the new management wanted to introduce. The president of the residential care home and the head manager of the cooperative explained the reasons for any activities that were contested, collecting suggestions about how the care service could be possibly improved. On that occasion, the president suggested that a permanent committee was set up for relatives in order to allow them to participate actively in the production and delivery of the service.

During the meeting, at the end of the various speeches, the president and the manager of the cooperative discussed many points with the families in detail. After this time, the relatives perceived a real openness on the part of both the president and the cooperative staff. The day after the meeting, the president set up a box for 
anonymous complaints, especially from relatives who did not want to express publicly their disapproval of certain initiatives. In general, the president is very aware of the relatives' points of view. Probably, the fact that he and one of members of the board of directors have a relative amongst the residents should not be overlooked.

The requests made by the relatives at the meeting were all taken into account. Thus, there was an increase in the time devoted to leisure activities (and to those initiatives, which are explained below as examples of co-production), changes were made in the lunch and dinner times, as well as in the scheduling of the patients' daily hygiene. Furthermore, the patients were once again allowed to access the living room after dinner and the proposal to set visiting hours for relatives was abolished. Family members can visit the residential home 24 h/day.

This first episode stimulated several activities, related in particular to treatment of patients and pain management, entertainment (through group activities), well-being and delivery of quality services. Concerning treatment and pain management, each patient has an Individualized Plan of Treatment (IPT), which is discussed in a meeting with his/her relatives every 6 months. This meeting is attended by the medical director, the psychologist, the physiotherapist, the leisure activity staff, the nurse, the patient's own nurses, the social assistants, the health workers and other service staff involved with the daily care, the patients and their relatives. In these meetings, relatives can request clarifications about the treatment, as well as provide suggestions to enhance patients' well-being. These circumstances also promote a greater dialogue between the professionals, discussing courses of treatment, as well as specific situations regarding each patient. Of course, the physicians are always available to meet the patients and their relatives to talk about any change in therapy.

Many other activities refer to leisure time, such as handcrafts for Easter, Christmas dinner, the narration of the patients' life on his/her birthday, the creation of vegetable gardens and the setting up of workgroups for ad hoc situations. These activities are coherent with well-established patterns of residents' well-being and health care, but each of them is characterized by a wider involvement of the patient in the design, planning and realization of the events. The design of the event is based on residents' experience, with an active role in the delivery of the service. Moreover, the majority of activities are organized with the involvement and participation of family members, as well as volunteers. Every day the volunteers deliver snacks to the patients and they help the staff to take patients to the living room on the ground floor.

During the Christmas period, for example, the patients are involved in the preparation of the Christmas dinner. Some patients provide their recipes to prepare the menu. Others are involved in handicrafts for the creation of the dishes (using a vegetable peeler), while others prepare various centrepieces for the table and decorations. Some volunteers and any family members available are involved in preparing the tables and decorations. A similar situation occurs during the monthly birthday party. The service staff chooses a couple of residents to tell their life story during the event. This moment requires quite a long preparation beforehand. During 
the days prior to the party, the service staff interact with the residents for the purpose of finding out about their lives, preparing what they will say at the party and how they will tell their story (i.e., with music, a movie, etc.). Moreover, since 2014, some patients have been involved in the process of preparing and attending to a vegetable garden near the residential care home. They choose themselves what kind of vegetables to plant, at which time, etc. Furthermore, the staff organises many leisure meetings with the involvement of volunteers and family members (i.e., a concert in the square of the town, bingo, harvest festivals, harvest-peeling and cleaning corn on the cob, cherry picking). Furthermore, in 2015, a psychologist and a staff assistant designed a patient team to participate in 10-12 meetings. This could be considered as an active way to share ideas between patients and service staff. Selected patients were asked to retrace their memories chronologically and present them with drawings or by cutting pictures from magazines. The psychologist did not interface family members, but the project allowed the professionals to build a more detailed patient profile about his/her habits, his/her experiences and the memories that affect the psychological condition positively and negatively.

Furthermore, the changes in the care delivery process has had an important impact on the participation of patients and their relatives in improving the quality of services. First of all, the new services and the wide availability of the service staff to co-produce the delivery of care with residents and relatives are described in the new service charter. Given the physical and mental conditions of the residents, the relatives played an essential and strategic role in this process of revision by expressing the residents' points of view, their desires and their expectations.

Therefore, thanks to the active role played by the relatives, the president and the manager of the cooperative compared the quality of service provided with the residents' needs. They planned an improved service delivery together with the relatives. In this way, as described above, a general increase in the quality of care has been achieved, in both the health and social care dimensions. More specifically, over the last two years there has been an increase in the number of minutes devoted per week to residents' care (from 600 to $901 \mathrm{~min} / \mathrm{week}$ ).

Moreover, through the relatives, the voice of the residents urged the board of directors of the residential care home to endorse the construction of a clinic for both residents and outpatients. In this way, residents have specialist care close to the residential care home and at lower costs. Furthermore, the fees of the residential care home remain unchanged thanks to the revenue from the outpatients.

The president is a key factor in this story. In fact, he is involved in a variety of internal and external initiatives that affect the service delivery inside, and promote a different way of considering the users' voices outside the residential care home. The president coordinates a round table with the other presidents of nearby residential care homes. During these meetings, the president describes the service delivery in his organisation and promotes a common understanding of the service management among the presidents of the other residential care homes around the table.

The president also participates in regional meetings where political groups represent a variety of territorial residential care homes. In this context, he promotes increased activity on the part of each political group to create circumstances in 
which residential care homes can show their experiences, discuss their problems about regional funds and norms and promote themselves as service innovators.

Finally, the president attended a specific master's course at university designed for residential care home managers. Academics organise this course combining frontal lectures with intensive empirical sessions in which each participant describes the processes and the activities run at their residential care homes. The president exploits these moments to reveal the users' points of view of service delivery. Moreover, he provides some examples of how the active involvement of patients and their relatives improves the quality of his residents' care.

\subsection{The Framework Based on Factors of Co-production: The Links Between Theory and Practice}

The case study could be interpreted through the relational approach described by Osborne and Strokosch (2013). According to the aim of the paper, at the operational and strategic levels, some factors may be identified that, empirically, imply the direct care and the organisational design and governance of the examined residential care. Figure 5.1 summarises these aspects.

Starting from the operational level, several activities in the case study refer to the residents' satisfaction (Abma and Baur 2014). Firstly, the co-produced treatment. As pointed out in previous studies (Carman et al. 2013), patients and their relatives are continuously involved with the service staff in the definition of diagnosis and in the search for the best treatment. In particular, residents and relatives have many informal possibilities to discuss their points of view about the care and health situation with the various residential figures. Doctors are available during their time at the residential care home in addition to meetings held three times a week. Furthermore, during the IPT meetings, the actors usually have an intense discussion about all the activities the residents are involved in. As Carman et al. (2013) argue, these circumstances increase the patients' knowledge about their own attitudes, their beliefs and previous experiences with the healthcare system. Moreover, as Abma and Baur (2014) emphasise, the recognition and the mutual understanding of underlying values are factors that promote co-produced activities at operational level. During the meetings with relatives, which in the case study is labelled as the first co-production episode, the process of establishment of a mutual understanding is evident.

Secondly, the quality of the health service regarding pain management (increasing the availability of doctors and service staff) and resident independence facilitation (availability of physiotherapists) increases. As the residents' perceptions of the quality of the health service were low, the new management introduced new services and practices through which patients and their relatives feel they share the responsibility for the treatment (Gilardi et al. 2014). In two cases, relatives reported that they decided on the physical treatments directly with one of the physiotherapists. In one case, a resident increased the frequency of gym activities thanks to the 


\begin{tabular}{|l|l|}
\hline Factors at Operational level \\
\hline $\begin{array}{l}\text { Pain management and } \\
\text { resident independence } \\
\text { facilitation }\end{array}$ \\
Group activities \\
Pense of safety and security
\end{tabular}

\section{Intertwined factors working at both levels}

The president and one of the members of the board of directors are both consumer and provider of the service.

The member of the board of directors is a member of the mayor's political party. The president and one of the members of the board of directors have frequent discussions with the mayor and people on the local government administration. The president suggested setting up a committee in order to participate formally in the decision-making.

The majority of activities implies the presence of many factors, i.e. trust, risktaking attitude, openness, facilitator and a sense of group affiliation and belonging. The president's participation on regional boards and in academic contexts. The mayor nominates both the president and the board of directors.

Fig. 5.1 Factors from the empirical evidence

collaboration of a physiotherapist and a relative. These new practices allow any party of the process to acknowledge the others (patients, families, doctors and all the residential home care staff) as a partner in creating a "well-being alliance" (Abma and Baur 2014; Gilardi et al. 2014).

Thirdly, the co-production activities allow access to a wide variety of group leisure activities. According to Abma and Baur (2014), storytelling, activities and events facilitate meaningful and appropriate social relationships, enforcing patients' attitudes (Carman et al. 2013; Gilardi et al. 2014), feelings and satisfaction among residents and their families (Abma and Baur 2014). Of particular importance is that the family is encouraged to maintain its involvement in the resident's life, given the emphasis placed on family contacts as a source of joy. Narration (Abma and Baur 2014) of the patients' life during the birthday parties is another factor that shows an intensive service co-production. 
Fourthly, some activities increase a sense of safety and security, enhancing the patients' peace of mind. The opportunity to meet the doctors increases the residents' sense of serenity and well-being. Some residents mentioned it specifically, while others just smile more than before.

Finally, although the physical environment is important, a positive social environment is vital. As well as receiving good care from them, residents appear to need to develop a positive relationship with staff members, and to feel that the staff is available to them when needed.

Further, researchers identify both organisational and local policy-making factors working at strategic level. As Osborne and Strokosch (2013) point out, the strategic level shows the participation of users in the design and planning of the services.

The first factor works at the organisational level. As described in the case study, the residential care home policy and the reorganization of the services have been introduced in the service charter, putting the focus on co-production activities. The meetings with the relatives allowed both the president and the manager of the cooperative to change their point of view about the quality and the service delivery. In this way, the participation of the relatives drives the organisational change in the residential home (Gilardi et al. 2014).

Even the second element works at the organisational level, referring to the general increase of the quality of care in both health and well-being aspects. As described before, the first meeting between the president and the relatives was crucial for increasing a common understanding of the quality of residential care. Families clearly expressed the importance of increasing the amount of time per day in which the residential staff interact with each resident. The real increase in the care provided affects the entire delivery of the service and the residential care home policies (Carman et al. 2013). Regarding the change of organisational policies and the entire organisational process, Carman et al. (2013) describe other specific factors. Empirically, similar factors refer to the re-arrangement of the personnel management, the increase of space dedicated to health and care provision with the hiring of four physicians, the increased awareness of costs and managerial aspects (e.g., the introduction of a nurse manager and a controller) and the open door policy for relatives. As in Carman et al.'s (2013) field of study, the patients' electronic health records are available on the residential care home intranet.

Contrary to the previous factors described so far, others work at the local policy-making level. The local government contributes towards the payment of the increased costs by endorsing the construction of outpatient clinics for both residents and non-residents. The outpatient clinics opened in May 2015. Thanks to the income of the outpatient clinics, the mayor and the president will keep residential rates at the current level. During both the meetings, many families expressed the impossibility to pay additional rates. Keeping in mind these problems, the mayor favoured the construction of these additional care facilities adding this project to his mandate. Thus, the researchers identify this element as evidence of the change of policy at the local government level.

All these co-produced activities show intertwined factors that enhance co-production at operative and strategic level. Indeed, according to the relational 
approach offered by Carman et al. (2013), activities that increase engagement at the policy-making level may intensify engagement or improve outcomes at the levels of direct care or organizational design and governance and vice versa.

In the case study, the researchers identify the innovative process of change and the values forwarded by the cooperative as an intertwined factor (Dunston et al. 2009). Additionally, an important factor that links improvements at both levels is the fact that the president of the residential care home and one of the members of the board of directors are both consumer and provider of the service. Furthermore, a member of the board of directors belongs to the same political party as the mayor. Both the president and this member have frequent discussions with the mayor and people on the local government administration. Both these statements are similar to what Bovaird and Loeffler (2012) refer to as overcoming the political and professional reluctance to lose status and control.

Subsequently, another important factor could reflect Bovaird and Loeffler's (2012) suggestion to develop the capacity of users and local communities. The circumstance refers to when the president of the residential care home suggested to the residents' families to set up a committee. The families' committee has not been established yet because the relatives already feel they are engaged in the decision-making.

In general, all the meetings organized by the president could be interpreted as an attempt to develop a sense of co-produced service and of group affiliation and belonging (Alford 2014). Furthermore, the presence of trust (Bovaird 2007; Abma and Baur 2014; Fledderus et al. 2015; Needham 2008; Verschuere et al. 2012), risk-taking (Bovaird 2007; Bovaird and Loeffler 2012), openness (Abma and Baur 2014), facilitator (Abma and Baur 2014; Alford 2014) and a sense of group affiliation and belonging (Alford 2014) are intertwined factors observed in the majority of activities described.

The central role of the president and his presence on important boards are related to the process of generating evidence of value for people (Bovaird and Loeffler 2012). Finally, a less perceived factor empirically is that the mayor nominates both the president and the board of directors and this aspect guarantees an intrinsic coordination between the operational and strategic level.

\subsection{Final Remarks and Agenda for Future Research}

The adoption of a co-produced perspective in the health and social care domain strengthens the focus on process analysis. The peculiarity of this field of study is the intrinsic interaction among the actors involved in the delivery and creation of services. The authors describe this characteristic as the relational approach in which actors could co-produce at "operational" and "strategic" level. This is the first recommendation of the chapter.

Following the Osborne and Strokosch (2013) approach, the researchers offer a systematisation of factors working at both the operational and strategic levels. 
Subsequently, they show how some factors work at both levels providing a clear link between the two levels. Researchers label these factors as intertwined factors. Although the authors map a few studies that associate factors with the level of analysis, none of them theorise intertwined factors. For this reason, this is the aim of the present study. The framework depicted in Table 5.1 is the second recommendation of the chapter.

As Osborne and Strokosch (2013) theoretically assume, the integration of co-production at both the operational and strategic levels transforms service delivery and co-creates new public services. This is the case of the services (for residents and citizens) provided by the outpatients' clinics. The multitude of co-production activities working at operational and strategic levels gives rise to the delivery of the most needed healthcare services. Thus, the third recommendation of the chapter refers to what Osborne and Strokosch (2013, p. S31) called the "potential for transformational change in public services".

Scholars could benefit from these theoretically and empirically based recommendations to nurture further ideas and investigations. Practitioners (i.e., public managers and consultants) could develop their understanding about co-production through the examples of factors working at operational and strategic level. In particular, the integration between service management and public management perspectives drives practitioners in the field to promote a co-production agenda. In political contexts where policy makers are not strong promoters of citizens' involvement, as in Italy, the framework provides the levers for the design and implementation of innovative co-produced public services.

\section{References}

T.A. Abma, V.E. Baur, User involvement in long-term care. Towards a relational care-ethics approach. Health Exp. 17, 1-12 (2014). doi:10.1111/hex.12202

J. Alford, Engaging Public Sector Clients: From Service-Delivery to Co-production (Palgrave Macmillan, Basingstoke, 2009)

J. Alford, The multiple facets of co-production: Building on the work of Elinor Ostrom. Pub. Man. Rev. 16, 299-316 (2014). doi:10.1080/14719037.2013.806578

S. Barello, G. Graffigna, M. Savarese, A.C. Bosio, Engaging patients in health management: Towards a preliminary theoretical conceptualization. Psi Sal. 3, 11-33 (2014). doi:10.3280/ PDS2014-003002

T. Bovaird, Beyond engagement and participation: User and community coproduction of public services. Pub. Man. Rev. 846-860 (2007). doi:10.1111/j.1540-6210.2007.00773.x

T. Bovaird, E. Löeffler, From engagement to co-production: The contribution of users and communities to outcomes and public value. Voluntas 23, 1119-1138 (2012). doi:10.1007/ s11266-012-9309-6

E. Bracci, D. Chow, When is personalisation considered a form of co-production? The case of Personal Budgets reform in English social care, eds. by E. Bracci, M.G. Fugini, M. Sicilia (Co-production in the Public Sector, Springer, 2016)

D. Burns, P. Hyde, A. Killett, F. Poland, R. Gray, Participatory organizational research: Examining voice in the co-production of knowledge. Br. J. Manag. 25, 133-144 (2012). doi:10.1111/j.1467-8551.2012.00841.x 
K.L. Carman, P. Dardess, M. Maurer, S. Sofaer, K. Adams, C. Bechtel, J. Sweeney, Patient and family engagement: A framework for understanding the elements and developing interventions and policies. Health Aff. 32, 223-231 (2013). doi:10.1377/hlthaff.2012.1133

N.K. Denzin, The Research Act in Sociology (Aldine, Chicago, 1970)

R. Dunston, A. Lee, D. Boud, P. Brodie, M. Chiarella, Co-production and health system reformFrom re-imaging to re-making. Aust. J Pub Adm. 68, 39-52 (2009). doi:10.1111/j.1467-8500. 2008.00608.x

J. Fledderus, T. Brandsen, M.E. Honingh, User co-production of public service delivery: An uncertainty approach. Pub. Policy Adm. 30, 145-164 (2015). doi:10.1177/0952076715572362

S. Gilardi, C. Guglielmetti, S. Casati, P. Monti, Promuovere l'engagement dei pazienti con malattie croniche: Un percorso di ricerca collaborativa. Psi Sal. 3, 58-79 (2014). doi:10.3280/ PDS2014-003004

W. Kickert, State responses to the fiscal crisis in Britain, Germany and the Netherlands. Pub. Man. Rev. 14, 299-309 (2012). doi:10.1080/14719037.2011.637410

C. Needham, Realising the potential of co-production: Negotiating improvements in public services. Soc. Policy Soc. 7, 221-231 (2008). doi:10.1017/S1474746407004174

S.P. Osborne, K. Strokosch, It takes two to Tango? Understanding the co-production of public services by integrating the services management and public administration perspectives. Br. J. Manag. 24, S31-S47 (2013). doi:10.1111/1467-8551.12010

S.P. Osborne, Z. Radnor, G. Nasi, A new theory for public service management? Toward a (public) service-dominant approach. Am. Rev. Pub. Adm. 43, 135-158 (2012). doi:10.1177/ 0275074012466935

E. Ostrom, Governing the Commons: The Evolution of Institutions for Collective Action (Cambridge University Press, New York, 1990)

C. Scott, K. Baehler, Adding Value to Policy Analysis and Advice (UNSW Press, Sydney, 2011)

M. Sorrentino, C. Guglielmetti, S. Gilardi, M. Marsilio, Health care services and the co-production puzzle: Filling in the blanks. Adm. Soc. 9, 1-26 (2015). doi:10.1177/0095399715593317

B. Verschuere, T. Brandsen, V. Pestoff, Co-production: The state of the art in research and the future agenda. Voluntas 23,1083-1101 (2012). doi:10.1007/s11266-012-9307-8 